\title{
Surface Distress Index Updates to Improve Crack Damage Evaluation
}

\author{
Bagus Hario Setiadji, Supriyono, and Djoko Purwanto
}

\begin{abstract}
Road pavement is one of infrastructures that is currently getting most attention due to its important role in accelerating the economic growth rate of an area, opening up isolated regions and improving the connectivity among them. A road infrastructure has a life-cycle which starts from design to reconstruction. Among all phases of road life-cycle, maintenance work plays an important role to maintain the performance of the road always in the top level. To conduct road maintenance work, it is necessary to evaluate the condition of the road, both structurally and functionally. To date, road functional condition assessment uses two indices, namely surface distress index (SDI) and international roughness index (IRI). The SDI, currently used by Directorate General of Highway (DGH), has a simple procedure and is easy to use. Talking about accuracy in estimating the functional conditions of the road, it seem that SDI is still far from satisfactory. In this study, an attempt to evaluate SDI, particular for crack damages, will be proposed by considering all types of crack damage and their corresponding dimension and severity level. Pavement condition index (PCI), the most comprehensive method for evaluating the functional conditions of the road, will be used as the reference. It looks like that PCI is the best choice as a tool to evaluate road functional conditions in Indonesia, however, the weak capability of the field personnel becomes a constraint in optimizing the potential of PCI. Therefore, updating SDI could be now considered as the best solution.
\end{abstract}

Index Terms - crack damage. road functional condition, SDI,

\section{INTRODUCTION}

$\mathbf{M}_{\mathrm{p}}$ aintenance/rehabilitation activity is one important part of road life cycle. To be able to select and implement a maintenance/rehabilitation program, a highway agency needs to ensure the latest condition of the road segment and also available budget, so that only the most appropriate program should be processed. This highlights the importance of the road condition evaluation process. The evaluation process

B.H. Setiadji is with the ${ }^{1}$ Department of Civil Engineering, Diponegoro University, 50275, Semarang, Central Java, Indonesia (email: bhsetiadji@ft.undip.ac.id)

Supriyono is with the ${ }^{1}$ Department of Civil Engineering, Diponegoro University, 50275, Semarang, Central Java, Indonesia

D. Purwanto is with the ${ }^{1}$ Department of Civil Engineering, Diponegoro University, 50275, Semarang, Central Java, Indonesia. consists of two parts, namely evaluation of functional and structural conditions.

The evaluation of functional condition is carried out to determine whether the road still has an adequate level of performance to be able to carry out its functions. The evaluation on flexible pavement usually consists of 3 components, namely, evaluation of the type and severity level of road damage, evaluation of the road roughness and evaluation of skid resistance of the road.

For road damage evaluation, there are two types of parameters that are used to define the level of road damage in Indonesia, that is, surface distress index (SDI) and road condition index (RCI). So far, RCI is less popular due to its qualitative manner in measuring the road damage. At present, a relationship has been developed between RCI and IRI (international roughness index) [1], however, this relationship is not appropriate since the two parameters are different philosophically and not all road damage contributes to the road roughness.

On the other hand, SDI is a parameter that is more widely used. This parameter, together with IRI, could represent the functional conditions of a road pavement. The use of IRI only can represent the roughness along the trail of wheel; therefore, combining the two parameters (SDI and IRI) is more effective in representing the damage of road surface. Unfortunately, SDI parameter is too simple as it only evaluates 3 types of road damage (i.e. pothole, crack and rut), compared to 19 types of road damage identified in PCI (pavement condition index) method $[2,3]$.

PCI method is recognized by AASHTO [4] as one of the most comprehensive methods in estimating the functional condition of a road. However, with such a comprehensive level, the procedure for determining PCI parameter becomes too complex. This is where the advantages and disadvantages of SDI parameter can play a role. The strength of SDI is in terms of simplicity and ease of conducting measurement of functional conditions of the road by surveyors with low to middle level education. On the other hand, the weakness of SDI is that simplification can lead to inaccuracies in estimating the functional condition of the road, which in turn will affect the inaccuracy of the selection of road handling types.

Based on the description above, this research is important to do especially for the following: (i) updating 
SDI parameter, especially for crack damage, so that SDI for crack damage can accommodate all types of crack, but with simplicity in its use; and (ii) the development of effective and efficient data collection procedure as a support for obtaining quality data, especially in terms of the level of detail and clarity of legibility. The purpose of this study was to update SDI, especially for crack damage, taking into account all types of crack damage, density and level of severity.

\section{PAVEMEnt Condition RATING}

\section{A. Pavement Condition Index (PCI)}

Pavement condition index (PCI) is a numerical index between 0 and 100 which is used to indicate the general condition of a pavement. PCI method identify 19 types of road distress, six of them are in category of crack damage. Each distress is characterized by its level severity and density. Both of them are used to determine a deduct value. Deduct value are numbers that represent the effects that distresses have on a pavement's structural integrity and surface operational condition [5]. This value then will be used to subtract from 100 to give the PCI value.

Each type of damage has a different level of severity, which will give different deduct value (see Fig. 1). By observing the magnitude of the deduct value (as shown on both deduct value charts in Fig. 1), one can estimate which type of damage contributes higher damage to the road, so that it is expected that priority can be given to handling the type of damage.
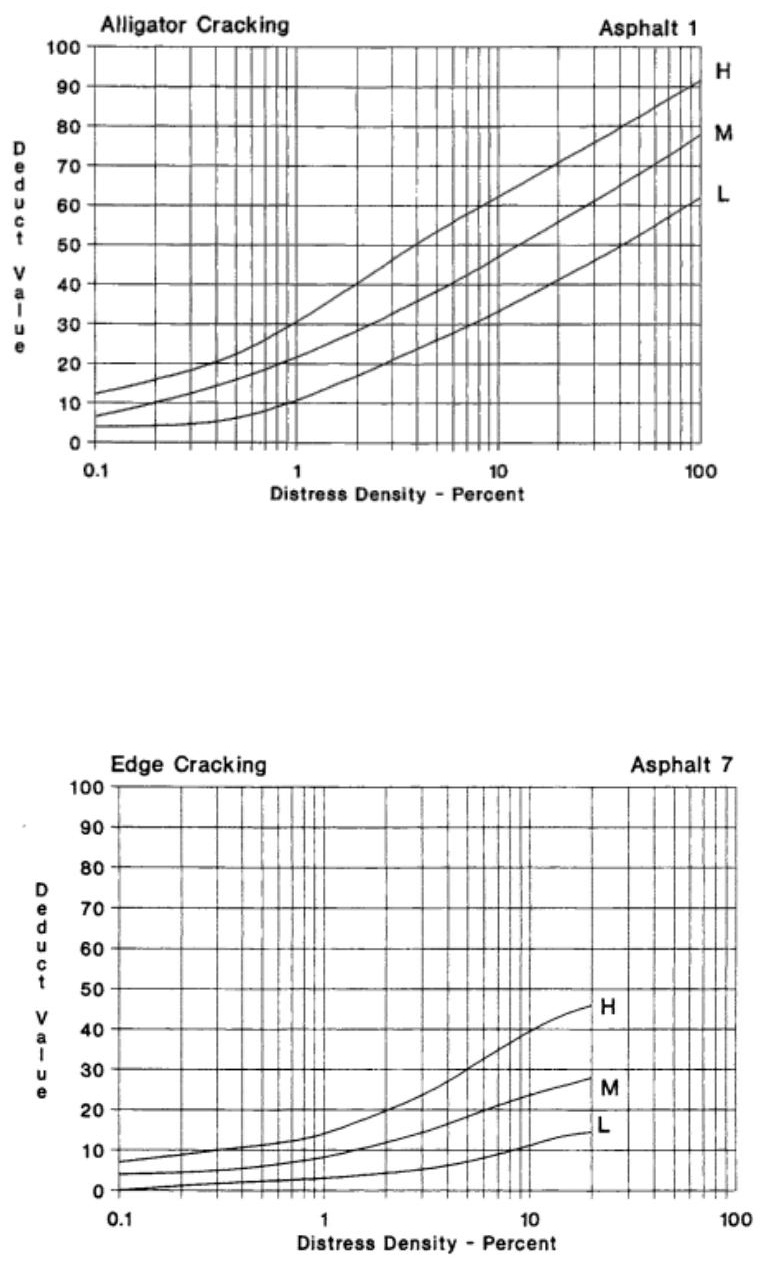

Fig. 1. PCI's Deduct Value Chart for Different Types of Cracking

\section{B. Surface Distress Index (SDI)}

The Directorate General of Highways uses an index that is different from PCI to state the condition of a road. There are three fundamental differences between SDI and PCI: (i) SDI states the condition of a road pavement based on only 3 types of damage, namely cracks, potholes and ruts, compared to PCI which encapsulates 19 types of damage; (ii) The value of deduct value in the PCI method is a function of 3 variables, namely type, severity and damage dimensions, while the SDI method does not always involve the severity and dimensions of damage in identifying a damage; and (iii) Damage in the PCI method functions as a deduction value of the absolute value of 100 , while the value that states the damage in SDI is cumulative, with the total value of damage equals to 325 . SDI values for different types of distress are depicted in Table I.

Based on Table I, SDI values for cracks, potholes and ruts are maximum 80,225 , and 320 , respectively. Based on the values, it can be seen that the greatest damage value is contributed by potholes. As shown in Table I, there is no difference of SDI for different types of crack damage, whereas in PCI method there are 6 different types of crack damage, with alligator crack type giving the biggest contribution. In addition, as seen in the table, only crack damage with the highest level of severity is taken into account in the calculation of SDI.

TABLE I

DISTRESS VALUATION IN SDI METHOD [1]

\begin{tabular}{ccll}
\hline $\begin{array}{c}\text { Distress } \\
\text { type }\end{array}$ & Parameter & \multicolumn{1}{c}{ Category } & \multicolumn{1}{c}{ SDI value } \\
\hline Cracks & Total area of & None & $\mathrm{SDI}_{1}=0$ \\
& cracks & $<10 \%$ & $\mathrm{SDI}_{1}=5$ \\
& (level 1) & $10 \%-30 \%$ & $\mathrm{SDI}_{1}=20$ \\
& & $>30 \%$ & $\mathrm{SDI}_{1}=40$ \\
& Average crack & None & $\mathrm{SDI}_{2}=\mathrm{SDI}_{1}$ \\
& width & $<1 \mathrm{~mm}$ & $\mathrm{SDI}_{2}=\mathrm{SDI}_{1}$ \\
& (level 2) & $1-3 \mathrm{~mm}$ & $\mathrm{SDI}_{2}=\mathrm{SDI}_{1}$ \\
& & $>3 \mathrm{~mm}$ & $\mathrm{SDI}_{2}=\mathrm{SDI}_{1} * 2$ \\
Potholes & Total no. of & None & $\mathrm{SDI}_{3}=\mathrm{SDI}_{2}$ \\
& potholes & $<10 / \mathrm{km}$ & $\mathrm{SDI}_{3}=\mathrm{SDI}_{2}+15$ \\
& (level 3) & $10 / \mathrm{km}-50 / \mathrm{km}$ & $\mathrm{SDI}_{3}=\mathrm{SDI}_{2}+75$ \\
& & $>50 / \mathrm{km}$ & $\mathrm{SDI}_{3}=\mathrm{SDI}_{2}+225$ \\
Rutting & Average & None & $\mathrm{SDI}_{4}=\mathrm{SDI}_{3}$ \\
& depth of & $<1 \mathrm{~cm}$ & $\mathrm{SDI}_{4}=\mathrm{SDI}_{3}+2.5$ \\
& wheel rutting & $1 \mathrm{~cm}-3 \mathrm{~cm}$ & $\mathrm{SDI}_{4}=\mathrm{SDI}_{3}+10$ \\
& (level 4$)$ & $>3 \mathrm{~cm}$ & $\mathrm{SDI}_{4}=\mathrm{SDI}_{3}+20$ \\
\hline
\end{tabular}




\section{RESEARCH METHODOLOGY}

This research methodology can be divided into 3 main parts:

a. Development of proposed road condition survey (RCS)

The survey method developed in this study is to provide solution on the existing survey method which is considered as not practical, although the results produced are quite accurate. The impracticability of the existing method is due to a compromise between the necessity to do a quick manual survey and to cover a fairly wide survey area, but with accurate results. To overcome this, the research proposed a survey method which is able to conduct the quickly and cover large areas without using modern surveying tools such as dedicated surveying vehicle. In the survey method developed, the equipment used consists of:

(i) four-wheel vehicle,

(ii) video camera (in this case GoPro Hero 6 video camera is used) and the application installed into the smartphone to monitor road conditions,

(iii) speed and distance monitoring software

To find out about the camera's mounting position (height and angle), trials using different height and angle positions of the camera were carried out. The camera height position is related to on which part of the vehicle that the camera video is ideally to put. The vehicle part will also determine the stability of the camera against the shake during the survey, while the camera angle will determine the extent of the camera coverage. For the height of the camera, placing the camera in range of $30-60 \mathrm{~cm}$ high, while the camera video angles considered were $30^{\circ}$ and $45^{\circ}$.

b. Development of proposed method to determine SDI The proposed SDI method is a method that adopts some parts of PCI determination method, namely by considering 3 variables: the type of damage, the level of severity of damage and the dimension of damage. The proposed SDI determination procedure is as follows:

(i) Determine the value of the deduct value (using the deduct value chart from PCI method, see Fig. 1) of 7 types of crack damage (alligator cracking, transverse cracking, longitudinal cracking, block cracking, edge cracking, joint reflection cracking, slippage cracking) for 3 severity level based on possible hypothetical density data. Density is obtained by dividing the area of damage by the area surveyed.

(ii) Since the maximum value of SDI for crack damage from the existing method is 80 , then all deduct value calculated using points (i) must be recalculated so that the SDI value for one type of crack damage, at a certain level of severity and density cannot exceed 80 . Evaluation of the maximum SDI value of 80 will be made further after two other types of damage from SDI have been determined in further work.

(iii) Development of density - SDI charts for all three severity levels for all types of damage

c. Determination of SDI using the results of RCS

To validate the method developed, several cases using hypothetical data will be proposed. In these cases, the type of damage, level and extent of damage will be combined to see how far the proposed method can give an idea of how robust the proposed SDI value can represent variations in type, severity and extent of damage that can occur. To be able to see the difference between the existing and proposed SDI values, the SDI value of the proposed cases will be compared to the existing SDI value.

\section{RESUlts AND DiscussiON}

\section{A. Development of Survey method}

Two types of vehicles were used during the survey, i.e. city car and small multi-purpose vehicle, to see the possibility of installing the video camera on different survey vehicles. The most important thing in the preparation before carrying out the survey is to install the video camera on the vehicle, that is, (a) finding out the suitable position (at the front grille or licence plate, for example) to ensure that the camera is attached firmly; (b) the height position of the camera; and (c) the angle position of the camera tilt (see Fig. 2).
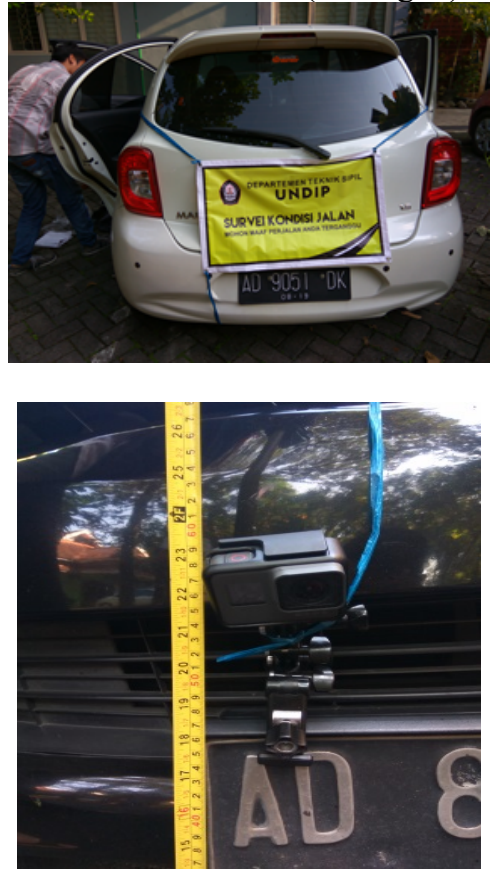


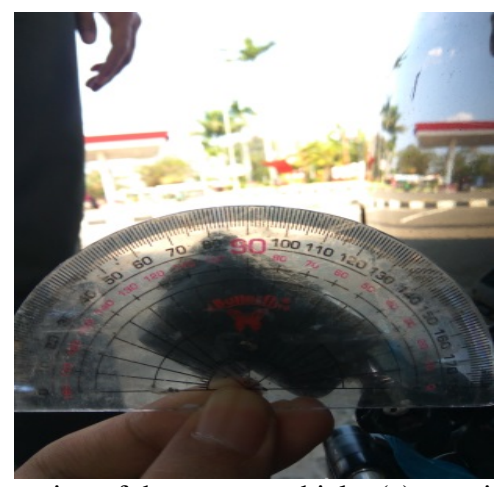

Fig. 2. Preparation of the survey vehicle: (a) warning sign at the back of vehicle; (b) height position of video camera; (c) angle position of video camera tilt

After several trials, it is decided that the best position of the video camera was on the height 45- 50 $\mathrm{cm}$ above pavement surface and on the angle tilt $45^{\circ}$. As the result, one could see the video of the distress on one lane clearly. The use of lower height and less angle tilt could cause the video produced to be convex and uncomfortable when viewed during analysis.

The selection of vehicle speed during the survey is another important matter that needs attention. Three ranges of vehicle speed have been tried during the survey, i.e. $10-20 \mathrm{~km} / \mathrm{h}, 30-40 \mathrm{~km} / \mathrm{h}$ and $50-60 \mathrm{~km} / \mathrm{h}$. Low speed range has an advantage in producing clearer survey results, while high speed range will be beneficial if the survey has to cover a wide area. In addition, the use of appropriate speed should also consider the road function. Therefore, the use of a warning sign is very important to warn road users of the obstacles in front of them in the form of road condition survey (see Fig. 2 (a)).

In this study, the speed range of $10-20 \mathrm{~km} / \mathrm{h}$ was selected with the consideration that this speed range could provide a fairly clear observation result. The use of speed and distance software will help driver to constantly maintain vehicle speed during the survey

After the survey, identification of types, level severity and dimension of distress were conducted using software. It is suggested that the software used has an ability to slow down the frame rate of the video so that detail observations of the results can be performed. The identification of the distress consists of: (a) six types of crack; (b) three levels of severity: high, medium and low according to Shahin [2] and ASTM [3]; (c) four width of distress area: $1 / 4,1 / 2,3 / 4$ and full of lane width; and (d) length of crack damage based on the length of the dimension monitoring software measurement.

\section{B. Proposed method to determine SDI for crack damage}

Deduct value chart in Fig. 1 is an empirical result based on works by Shahin and Kohn [5]. A conversion of deduct value to SDI value was conducted in this study by utilizing hypothetical data. A maximum value of SDI equals to 80 was used as reference in this conversion due to no detail information available regarding with conversion factor for each severity level. Maximum deduct value per severity level for all types of cracks were identified and ratios among these values to maximum possible deduct value then were calculated. The ratios, together with maximum possible SDI or equals to 80 , were used to develop proposed SDI charts, as seen in Fig. 3.

Fig. 3 shows that three types of cracks could cover entirely of evaluated area, i.e. alligator, block and slippage cracking (as stated by Shahin [2] and ASTM [3]) as indicated by density value reaching $100 \%$. However, the distress area is not the main factor that causes high SDI, as shown by SDI between block and longitudinal/transversal cracking. As seen in the figure, longitudinal/transversal cracking contributes the highest value of SDI on $30 \%$ density than other cracks; however, slippage and alligator cracks have the highest impact on the road condition if these two distresses found in the field at a large area.

To ensure that the proposed SDI could be used properly, a validation was conducted by considering varied conditions that could be encountered in practice. To do so, the equations developed for different crack types and levels of severity, and also hypothetical data were used. Eight cases were considered in which each case could consist of different numbers of cracks, density and level of severity, as seen in Table II.

As seen in Table II, existing SDI value only differs depending on the area of the distress and is not affected by the type and level of severity of the cracks. In fact, despite the high severity of damage, as shown by case $\# 3$, the SDI values obtained are the same as if the severity is low and medium.

Different results are shown by the proposed SDI, where with the same crack area, SDI values can be different, depending on the type and severity level of the crack, as shown in case \# 3 up to case \# 6. Even in high density condition, it will not necessarily contribute to high SDI values, as shown by the comparison between case \# 7 and case \# 8.

SDI is a composite index that indicates the level of damage to a road, this causes the sum of SDI values from different crack types will cause the total SDI value to exceed the maximum allowable value. Unlike the PCI method, where the total deduct value has to be reduced proportionally so that the final calculation of the PCI value should not be negative, the total SDI value for crack damage that is greater than the maximum allowable value, i.e. 80 , will be equated to the maximum value. An example is case \# 2 where the total SDI value is 106.54 , so in calculation, the total SDI value will be equal to the maximum allowable SDI value for crack damage, which is equal to 80 . 

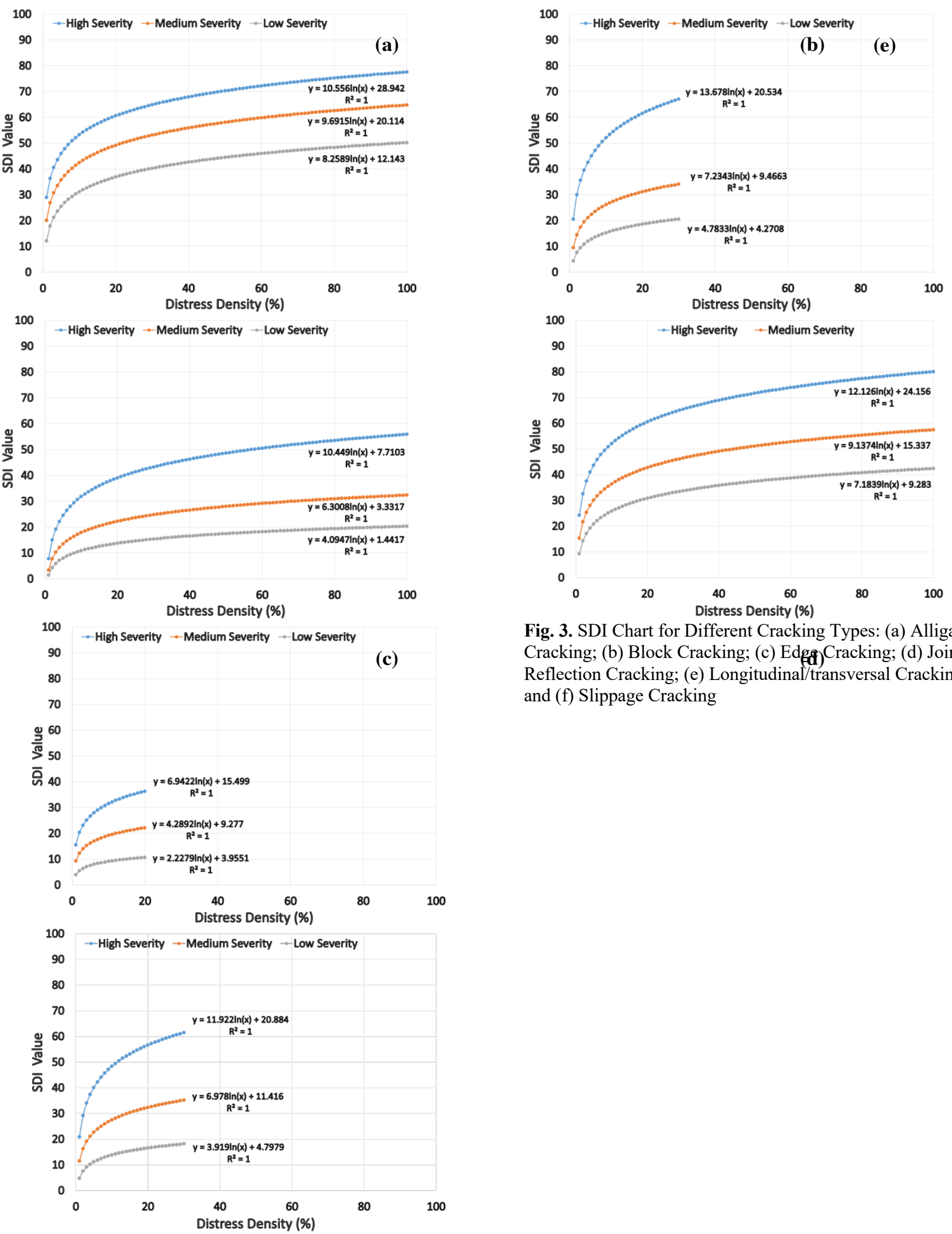

Fig. 3. SDI Chart for Different Cracking Types: (a) Alligator Cracking; (b) Block Cracking; (c) Edgd) Cracking; (d) Joint Reflection Cracking; (e) Longitudinal/transversal Cracking; and (f) Slippage Cracking

TABLE II

COMPARISON BETWEEN PROPOSED AND EXISTING SDI 


\begin{tabular}{|c|c|c|c|c|c|c|c|c|c|c|c|c|c|}
\hline \multirow{2}{*}{$\begin{array}{l}\text { No. of } \\
\text { Cases }\end{array}$} & \multirow{2}{*}{$\begin{array}{c}\text { Density } \\
(\%)\end{array}$} & \multirow{2}{*}{$\begin{array}{l}\text { Level of } \\
\text { Severity }\end{array}$} & \multicolumn{9}{|c|}{ Proposed SDI } & \multicolumn{2}{|c|}{ Existing SDI } \\
\hline & & & $\begin{array}{l}\text { Alligator } \\
\text { (1) }\end{array}$ & $\begin{array}{c}\text { Block } \\
\text { (2) }\end{array}$ & $\begin{array}{l}\text { Longitu- } \\
\text { dinal (3) }\end{array}$ & \begin{tabular}{|c|} 
Trans- \\
verse (4)
\end{tabular} & $\begin{array}{c}\text { Edge } \\
(5)\end{array}$ & \begin{tabular}{|c|} 
Joint Ref. \\
(6)
\end{tabular} & \begin{tabular}{|c|} 
Slippage \\
(7)
\end{tabular} & \begin{tabular}{|c|} 
Total SDI \\
(calculate d)
\end{tabular} & $\begin{array}{l}\text { Total SDI } \\
\text { (adjuste d) }\end{array}$ & $\begin{array}{c}\% \text { Cracking } \\
\text { Area }\end{array}$ & Total SDI \\
\hline \multirow{2}{*}{$\# 1$} & 17.00 & $1 \mathrm{M}$ & 48.81 & 0.00 & 0.00 & 0.00 & 0.00 & 0.00 & 0.00 & \multirow{2}{*}{85.83} & \multirow{2}{*}{80.00} & \multirow{2}{*}{26.00} & \multirow{2}{*}{40.00} \\
\hline & 9.00 & $7 \mathrm{M}$ & 0.00 & 0.00 & 0.00 & 0.00 & 0.00 & 0.00 & 37.02 & & & & \\
\hline \multirow{4}{*}{ \#2 } & 10.00 & $3 \mathrm{M}$ & 0.00 & 0.00 & 26.52 & 0.00 & 0.00 & 0.00 & 0.00 & \multirow{4}{*}{106.54} & \multirow{4}{*}{80.00} & \multirow{4}{*}{28.00} & \multirow{4}{*}{40.00} \\
\hline & 10.00 & $5 \mathrm{M}$ & 0.00 & 0.00 & 0.00 & 0.00 & 21.38 & 0.00 & 0.00 & & & & \\
\hline & 5.00 & $1 \mathrm{~L}$ & 26.39 & 0.00 & 0.00 & 0.00 & 0.00 & 0.00 & 0.00 & & & & \\
\hline & 3.00 & $1 \mathrm{M}$ & 32.24 & 0.00 & 0.00 & 0.00 & 0.00 & 0.00 & 0.00 & & & & \\
\hline \multirow{3}{*}{$\# 3$} & 10.00 & $1 \mathrm{H}$ & 54.27 & 0.00 & 0.00 & 0.00 & 0.00 & 0.00 & 0.00 & \multirow{3}{*}{130.02} & \multirow{3}{*}{80.00} & \multirow{3}{*}{30.00} & \multirow{3}{*}{40.00} \\
\hline & 10.00 & $1 \mathrm{M}$ & 43.74 & 0.00 & 0.00 & 0.00 & 0.00 & 0.00 & 0.00 & & & & \\
\hline & 10.00 & $1 \mathrm{~L}$ & 32.01 & 0.00 & 0.00 & 0.00 & 0.00 & 0.00 & 0.00 & & & & \\
\hline \multirow{3}{*}{$\# 4$} & 10.00 & $4 \mathrm{M}$ & 0.00 & 0.00 & 0.00 & 26.52 & 0.00 & 0.00 & 0.00 & \multirow{3}{*}{75.75} & \multirow{3}{*}{75.75} & \multirow{3}{*}{30.00} & \multirow{3}{*}{40.00} \\
\hline & 10.00 & $5 \mathrm{M}$ & 0.00 & 0.00 & 0.00 & 0.00 & 21.38 & 0.00 & 0.00 & & & & \\
\hline & 10.00 & $6 \mathrm{M}$ & 0.00 & 0.00 & 0.00 & 0.00 & 0.00 & 27.84 & 0.00 & & & & \\
\hline \multirow{6}{*}{$\# 5$} & 5.00 & $1 \mathrm{M}$ & 37.12 & 0.00 & 0.00 & 0.00 & 0.00 & 0.00 & 0.00 & \multirow{6}{*}{121.87} & \multirow{6}{*}{80.00} & & \\
\hline & 5.00 & $2 \mathrm{M}$ & 0.00 & 5.68 & 0.00 & 0.00 & 0.00 & 0.00 & 0.00 & & & & \\
\hline & 5.00 & $3 \mathrm{M}$ & 0.00 & 0.00 & 15.97 & 0.00 & 0.00 & 0.00 & 0.00 & & & 3000 & 4000 \\
\hline & 5.00 & $5 \mathrm{M}$ & 0.00 & 0.00 & 0.00 & 0.00 & 14.66 & 0.00 & 0.00 & & & 30.00 & 40.00 \\
\hline & 5.00 & $6 \mathrm{M}$ & 0.00 & 0.00 & 0.00 & 0.00 & 0.00 & 17.12 & 0.00 & & & & \\
\hline & 5.00 & $7 \mathrm{M}$ & 0.00 & 0.00 & 0.00 & 0.00 & 0.00 & 0.00 & 31.31 & & & & \\
\hline & 5.00 & $1 \mathrm{~L}$ & 26.39 & 0.00 & 0.00 & 0.00 & 0.00 & 0.00 & 0.00 & & & & \\
\hline & 5.00 & $2 \mathrm{~L}$ & 0.00 & 3.05 & 0.00 & 0.00 & 0.00 & 0.00 & 0.00 & & & & \\
\hline$\# 6$ & 5.00 & $3 \mathrm{~L}$ & 0.00 & 0.00 & 8.61 & 0.00 & 0.00 & 0.00 & 0.00 & 73,31 & 73.31 & 3000 & 4000 \\
\hline$\# 0$ & 5.00 & $5 \mathrm{~L}$ & 0.00 & 0.00 & 0.00 & 0.00 & 6.77 & 0.00 & 0.00 & 13.21 & 13.31 & 30.00 & 40.00 \\
\hline & 5.00 & L & 0.00 & 0.00 & 0.00 & 0.00 & 0.00 & 7.04 & 0.00 & & & & \\
\hline & 5.00 & $7 \mathrm{~L}$ & 0.00 & 0.00 & 0.00 & 0.00 & 0.00 & 0.00 & 21.45 & & & & \\
\hline$\# 7$ & 27.00 & $1 \mathrm{M}$ & 53.23 & 0.00 & 0.00 & 0.00 & 0.00 & 0.00 & 0.00 & 83.43 & 8000 & 3500 & 8000 \\
\hline$\#$ I & 8.00 & $1 \mathrm{~L}$ & 30.20 & 0.00 & 0.00 & 0.00 & 0.00 & 0.00 & 0.00 & 80.45 & 0.00 & 35.00 & 0.00 \\
\hline$\# 8$ & 70.00 & $1 \mathrm{M}$ & 62.33 & 0.00 & 0.00 & 0.00 & 0.00 & 0.00 & 0.00 & 62.33 & 62.33 & 70.00 & 80.00 \\
\hline
\end{tabular}

This arrangement makes the SDI value from crack damage can still follow the existing procedure to calculate the final value of SDI, after the contribution of the pothole and rut damage is determined.

\section{RESUlts AND Discussion}

This paper presented a proposed survey method and procedure to determine surface distress index (SDI) that considering different types of distress, levels of severity and densities. It resulted in: (i) recommendation of lowspeed $(10-20 \mathrm{~km} / \mathrm{h})$ road condition survey with video camera height and angle tilt position of $45-50 \mathrm{~cm}$ and $45^{\circ}$, respectively; (ii) proposed SDI chart can be used to determine SDI values based on three variables: distress density, level severity and types of crack, instead of only distress density in the existing procedure; and (iii) total SDI value for crack damage that is greater than the maximum value, i.e. 80 , will be equated to that maximum value so that the value can be used in procedure to determine the final value of SDI.

\section{ACKNOWLEDGEMENT}

This research was financially supported by The Faculty of Engineering, Diponegoro University, Indonesia through Strategic Research Grant 2018. The authors also thank Gideon Alam Silaban and Indra Syahputra Nasution for assistance in survey and data compilation.

\section{REFERENCES}

[1] Directorate General of Highways, "Guidance of Road Condition Survey No. SMD-03/RCS," Ministry of Public Works Republic of Indonesia. Jakarta, 2011. (in Indonesian)
[2] M.Y. Shain, "Pavement Management for Airports, Roads, and Parking Lots," $2^{\text {nd }}$ Edition, Springer, USA, 2005.

[3] ASTM International, "Standard Practice for Roads and Parking Lots Pavement Condition Index Surveys," ASTM D6433-07, West Conshohocken, PA, 2007.

[4] Federal Highway Administration, AASHTO Pavement Management Guide, $2^{\text {nd }}$ Edition, Washington, DC, 2012.

[5] M.Y. Shahin, and S.D. Kohn, "Development of a Pavement Condition Rating Procedure for Roads, Streets, and Parking Lots, Vol. 1 Condition Rating Procedure," Technical Report M268. United States Army Corps of Engineers. Champaign, IL. USA, 1979. 
